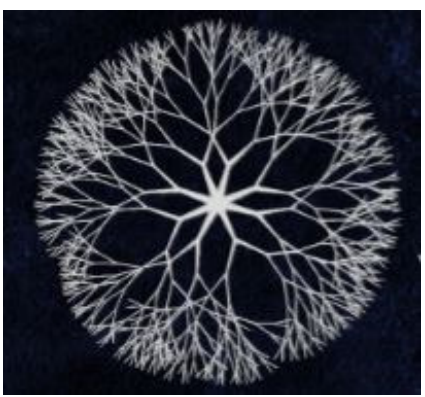

\title{
Elos possíveis entre a História das Ciências e a educação CTS
}

\author{
Rosângela Rodrigues de Oliveira \\ Mestre em Ensino, História e Filosofia das \\ Ciências e da Matemática - UFABC \\ rosanglaro@gmail.com
}

\author{
Márcia Helena Alvim \\ Doutora em História das Ciências - UNICAMP \\ Professora Associada na UFABC \\ marcia.alvim@ufabc.edu.br
}

Recebido em 15/04/2017. Aprovado em 29/06/2017.

Como citar este artigo: Oliveira, R. R.; Alvim, M. H. "Elos possíveis entre a História das Ciências e a educação CTS". Khronos, Revista de História da Ciência, nº 4, pp. 58 - 71. 2017. Disponível em < http://revistas.usp.br/khronos>. Acesso $\mathrm{em} \mathrm{dd} / \mathrm{mm} /$ aaaa.

Resumo: Neste artigo apresentamos uma reflexão sobre a aproximação entre História das Ciências e educação CTS, objetivando a construção de uma educação científica mais crítica e reflexiva. Para isso, partimos de uma análise teórico-reflexiva, através de uma revisão da literatura. Concluímos que há um panorama bastante positivo para adotarmos uma abordagem que interligue a HC e a educação CTS. Acreditamos que esta relação promove a ruptura das fronteiras entre os saberes e direciona-se na busca de um ensino problematizador, humano e reflexivo com os objetivos de formar cidadãos mais críticos e, quiçá, capazes de transformar a sociedade.

Palavras-chave: História das Ciências, Educação CTS, Educação Científica, Ensino de Química.

\section{Possible links between the History of Science and CTS Education}

\begin{abstract}
In this article, we present a reflection about the approximation between History of Sciences and STS study, aiming the construction of a more critical and reflective scientific education. For this, we start with a theoretical-reflexive analysis, through a literature review. We conclude that a very positive scenario comes from adopting an approach that links HS and STS study. We believe that this relationship promotes the breakdown of the boundaries between knowledge and is directed in the search for problematizing, human and reflexive education with the objectives of forming more critical citizens and, perhaps, capable of transforming society.
\end{abstract}

Keywords: History of Science, STS Study, Scientific Education, Chemistry Teaching. 


\section{Introdução}

Diversos trabalhos valorizam a utilização didática da História das Ciências - $\mathrm{HC}^{1}$ no ensino, quer seja em nível da educação básica ou de nível superior. Porém, o que observamos é que existe uma linha em crescimento e, portanto, ainda pouco explorada, ou seja, a que compreende a História das Ciências como agente de transformações e compreensão das interrelações entre ciência, sociedade, tecnologia e ambiente.

Da mesma maneira, vários estudos apontam para a importância de uma educação CTS 2 na qual a transdisciplinaridade favoreça o ensino de ciência e tecnologia, visando, principalmente, a formação de indivíduos críticos e ativos que entendam seu papel cidadão nas tomadas de decisões em assuntos relacionados à ciência, tecnologia, sociedade e ambiente, sendo capazes de julgar e emitir opiniões acerca da realidade que os cerca, fortalecendo e ampliando sua participação. Este artigo irá refletir sobre as possibilidades desta articulação para o ensino de ciências.

Apesar da HC e da educação CTS serem convencionalmente abordadas como linhas distintas de pesquisa, acreditamos que existam muitos pontos de convergência entre ambas. $\mathrm{O}$ principal deles, talvez, seja o reconhecimento de que as ciências e as tecnologias são frutos de um trabalho humano, inseridos em contextos sociais, culturais, políticos e ambientais particulares. Acreditamos que a compreensão destes contextos pode ser realizada através da pesquisa em HC e trabalhados, em sala de aula, a partir do enfoque CTS. ${ }^{3}$

O movimento CTS surgiu, nos anos 1970, com a finalidade de questionar a ciência e a tecnologia, apresentando, naquele momento, um viés bastante tecnocrático. A perspectiva CTS recebeu contribuições muito significativas da reflexão oriunda da história, filosofia e sociologia da ciência, da economia e da psicologia industrial, que pretendiam fomentar nos cientistas e tecnólogos a conscientização da projeção social do seu trabalho e uma melhor compreensão da ciência e da tecnologia junto ao público, com a finalidade de resolver problemas sociais com elas relacionados. ${ }^{4}$

Segundo Santos e Schnetzler compreendem os aspectos históricos que envolveram as ciências e as tecnologias permitem a realização de uma ancoragem entre determinados conteúdos científicos e tecnológicos e os aspectos sociais (economia, política, cultura e mesmo artística) neles embutido, apresentando aos estudantes a interligação entre diversos saberes e a suscetibilidade sócio-política-cultural inerente ao fazer ciência e sua relação com nossas vidas cotidianas ${ }^{5}$.

Como qualquer conteúdo científico arrasta atrás de si a sua própria história e esta não pode ser isolado dos fatores sociais e do contexto em que se desenvolveu, a história da ciência constitui-se como uma fonte muito rica, talvez a mais rica, de onde se possa extrair exemplos. Alguns serão mais atraentes do que outros, mas sempre será possível estabelecer tais conexões.

${ }^{1}$ Daqui para frente História das Ciências será tratada como HC.

${ }^{2}$ CTS - Ciência, Tecnologia e Sociedade.

3 OLIVEIRA, R. R.; OLIVEIRA, E. R. A bistória das ciências com foco na educação CTS e o ensino de química elos possíveis. V Simpósio Nacional de Ensino de Ciência e Tecnologia - SINECT. Ponta Grossa - PR, 2016.

4 ACEVEDO DÍAZ, J. A.; VÁZQUEZ ALONSO, A.; MANASSERO-MAS, M. A. El movimiento Ciencia, tecnología y sociedad y la enseñanza de las ciencias. Sala de Lecturas CTS+I de la OEI, 2002. Disponível em http://www.oei.es/historico/salactsi/acevedo13.htm .

${ }^{5}$ SANTOS, Wildson Luiz Pereira; SCHNETZLER, Roseli Pacheco Educação em Química: Compromisso com a cidadania. Ijuí: Unijuí, 2003. 
É uma questão de selecionar os casos mais interessantes e adequados dependendo das características dos alunos (educação, circunstâncias sociais e geográficas, maturidade e preparação, etc.). ${ }^{6}$

Neste sentido, a interligação de saberes pode ser realizada por meio de estudos e pesquisa em HC e educação CTS, pois isto permite o debate de questões contemporâneas que afetam nosso cotidiano e não somente as temáticas do passado. ${ }^{7} \mathrm{Da}$ mesma maneira, a história cultural pode permitir a análise da produção de conhecimentos, partindo de sua relação com o contexto sociocultural, econômico, político, etc. que interferem de maneira decisiva no desenvolvimento da ciência e tecnologia. ${ }^{8}$

Desta forma, a proposta do presente artigo é discutir a importância da história das ciências dentro de uma perspectiva CTS, através da prática reflexiva de professores, traçando elos possíveis entre estas duas linhas, destacando de que forma a HC pode contribuir para a compreensão das relações sociais no avanço das ciências e seu impacto na tecnologia, sociedade e ambiente. Para a consecução destes objetivos, nosso estudo está centrado em uma análise teórico-reflexiva de diferentes pesquisadores em história das ciências, educação CTS e ensino de ciências através de uma revisão da literatura, com o intuito de romper as fronteiras entre os diferentes saberes e direcionar um ensino de ciências mais problematizador, humano e reflexivo.

\section{HC na perspectiva CTS e o pensamento crítico/reflexivo}

O mundo está repleto de produtos oriundos dos avanços científicos e tecnológicos. Atualmente isto é algo tão natural que muitas vezes passa desapercebida as mudanças que ocorreram nos últimos tempos e o quanto de esforços foram empenhados para que a ciência e a tecnologia chegassem ao status que usufruem atualmente. Esta compreensão ou, sua ausência, impactam diretamente a visão que temos em relação às influências da ciência e tecnologia na natureza.

Diante disto Santos e Schnetzler ${ }^{9}$ levanta alguns questionamentos: Estamos conscientes da importância dos produtos da ciência e tecnologia que nos cercam? Percebemos os benefícios, perigos e desvantagens que também originam? Se refletirmos um pouco sobre estas questões, grande parte das respostas serão negativas e as fontes de informação de massa, as grandes mídias, trazem uma infinidade de informações distorcidas e, por vezes, enganosas sobre as questões relacionadas a ciência e tecnologia.

Assim, podemos nos questionar se a ciência e a tecnologia são de fato tão acessíveis quanto se pode pensar. O senso comum compreende a ciência como verdade absoluta, haja vista, os rótulos e discursos do "cientificamente comprovado". Esta crença em uma ciência infalível, neutra e benéfica precisa ser questionada pelos cidadãos a fim de que eles se apropriem adequadamente de conhecimentos e tenham uma compreensão clara que possibilite sua participação no processo democrático de tomada de decisão e resolução de problemas sociais relacionados à ciência e a tecnologia.?

${ }^{6}$ SANTOS e SCHNETZLER, 2003. Op. Cit. p. 403.

${ }^{7}$ FREIRE Jr., Olival relevância da filosofia e da história das ciências para a formação dos professores de ciências. In: Silva Filho, W. J. et al. Epistemologia e Ensino de Ciências, Salvador: Ed. Arcádia, 2002, p. 51-92.

8 ALVIM, Márcia Helena; ZANOTELLO, Marcelo. História das ciências e educação científica em uma perspectiva discursiva: contribuições para a formação cidadã e reflexiva. Revista Bras de História da Ciência, vol2, 2014.

${ }^{9}$ SANTOS e SCHNETZLER, 2003. Op. Cit. 
Neste sentido, um dos desafios do ensino de ciências na atualidade, apontado por pesquisadores (SANTOS; SCHNETZLER, 2003; CHASSOT, 2007; ABRANTES, 2002; SANTOS, 2009; PENHA, 2001) e pelos documentos oficiais (BRASIL, 2012, 2006, 2002, 2000) seria o de promover um pensamento crítico sobre a ciência e tecnologia na população escolarizada. Para Solbes ${ }^{10}$ um dos caminhos possíveis para alcançar este objetivo seria por meio da inserção de questões sociocientíficas, utilizando-se para isto a história e a sociologia da ciência, como instrumentos importantes na demonstração das controvérsias científicas, na reflexão crítica da construção do pensamento científico e desenvolvimento tecnológico, ou seja, através de uma educação CTS.

Jiménez-Aleixandre ${ }^{11}$ define pensamento crítico como: "[...] a capacidade de desenvolver uma opinião independente, adquirindo a capacidade de refletir sobre a sociedade e participar dela", neste sentido a educação CTS, por tratar de questões ambientais, tecnológicas e energéticas, que atingem diretamente a sociedade, pode contribuir para esta reflexão e, sob a perspectiva teórica da HC, através do diálogo com suas discussões historiográficas, pode contribuir para a compreensão das controversas na produção da ciência, dos diferentes interesses e valores sociais e políticos e, assim, promover o desenvolvimento de ideias e valores críticos na escola.

Esta tomada de consciência sobre a ciência e tecnologia é um processo contínuo, fruto de estudos e aquisição de novos significados para antigas práticas. Constitui-se como uma ruptura com velhos paradigmas, sendo essencial para a construção de novos saberes, para a apropriação de novos conhecimentos e, consequentemente para a emancipação cidadã, "A conscientização implica, pois, que ultrapassemos a esfera espontânea de apreensão da realidade, para chegarmos a uma esfera crítica na qual a realidade se dá como objeto cognoscível e na qual o homem assume uma posição epistemológica". ${ }^{12}$

Freire defende uma educação transformadora, que modifique o pensar e o agir. Considerando a educação como uma atividade eminentemente humana, onde devemos buscar um certo nível de conscientização que estimule a reflexão/ação, ou seja, uma busca incessante e permanente pela mudança, pela superação do ser passivo e da cultura do silêncio, possibilitando ao sujeito desenvolver posturas críticas. Neste sentido, a educação crítica e emancipadora perpassa, dentre outras propostas teóricas, a inserção dos debates CTS ao ensino, que impulsionados por reflexões da HC, constituem-se como um encaminhamento promotor de uma educação científica transformadora.

Quer dizer, mais do que um ser no mundo, o ser humano se tornou uma Presença no mundo, com o mundo e com os outros. Presença que, reconhecendo a outra presença como um "não-eu" se reconhece como "si própria". Presença que pensa a si mesma, que se sabe presença, que intervém, que transforma, que fala do que faz, mas também do que sonha, que constata, compara, avalia, valora, que decide, que rompe. ${ }^{12}$

O presente artigo busca promover esta perspectiva, pois, acreditamos que o pensamento crítico, deve-se principalmente à reflexão e esta é nutrida, não somente pelas práticas, mas também, por teorias que forneçam elementos de análise, fundamentação e questionamento da experiência. Ser um professor crítico/reflexivo como preconizado por Scön

10 SOLBES, J. Contribución de las cuestiones sociocientificas al desarrollo del pensamiento crítico (I): Introducción. Revista Eureka sobre Enseñanza y Divulgación de las Ciencias 10 (1), 1, 2013.

11 Jiménez-Aleixandre, 2010, in Solbes, Op. Cit.

12 FREIRE, 2006. Pedagogia da Autonomia: saberes necessários à prática educativa. $32^{\mathrm{a}}$ ed. São Paulo: Paz e Terra, 2006. p.20. 
demanda esforço, intencionalidade, compromisso e principalmente capacidade de abertura à mudança e ao novo, desconstruindo concepções e práticas rotineiras ${ }^{13}$. A HC focada em uma perspectiva CTS mostra-se mais do que mera ilustração histórica, episódica e cronológica, ela pode representar, para o professor, uma nova concepção reflexiva, onde o professor ao apropriar-se dos conteúdos de HC se torna capaz de fomentar uma reflexão crítica sobre a ciência e tecnologia contemporâneos.

\section{HC, Educação CTS e Ensino de Ciências}

Um dos principais objetivos do ensino de ciências é ajudar os alunos a compreenderem e superarem os obstáculos para a construção de conhecimentos, estabelecendo estratégias e conteúdo que permitam ao aluno realizar um trabalho cognitivo aglutinador, envolvendo diversas disciplinas. ${ }^{14}$ Entretanto, tais objetivos não estão sendo amplamente atingidos na educação básica, haja vista, as dificuldades e baixos índices de proficiência dos alunos brasileiros em ciências.

Quando analisamos mais especificamente o ensino de química, é comum nos depararmos com frustrações relacionadas às dificuldades dos alunos em compreender conteúdos químicos. Estas são inúmeras e das mais diversas ordens, tanto que Michel Mattews denomina de "mar de falta de significação" no ensino de ciências. ${ }^{15}$ Acreditamos que uma das maneiras de reduzir esta falta de significação está na compreensão do que vem a ser química e como ela foi sendo construída ao longo do tempo.

Alvim e Zanotello defendem que o ensino de ciências não deve ser limitado a mera resolução de exercícios e questionários fechados sobre diferentes conteúdos, mas devem promover a construção de uma cultura científica que situe as ciências historicamente, relacionando-as com seus aspectos sociais, econômicos e políticos ${ }^{16}$.

Situamo-nos ao lado daqueles que defendem a ideia de que o ensino escolarizado das ciências não deve se limitar ao desenvolvimento de uma capacidade aguçada para fazer exercícios e responder questionários fechados sobre certos conteúdos, mas também envolver a construção de uma cultura científica, fazendo com que o estudante adquira noções sólidas sobre o que as ciências produzem, quais seus objetos de estudo, como elas se desenvolvem historicamente e como se relacionam no mundo contemporâneo com as esferas social, econômica e política.

Neste mesmo sentido, Fernández considera que o ensino de química, em uma perspectiva histórica, adquire importância quando incorpora aspectos envolvidos na gênese e evolução dos conceitos científicos, permitindo dimensionar o caráter mutável das ciências, desfazendo a imagem de neutralidade científica e compreendendo-a como um processo de construção com dimensões sociais, políticas e culturais ${ }^{17}$.

${ }^{13}$ SCHÖN, Donald A. Educando o profissional reflexivo: um novo design para o ensino e a aprendizagem. Trad. Roberto Cataldo Costa. Porto Alegre: Artes Médicas Sul, 2000.

14 BRASIL. Ministério da Educação, Secretaria da Educação Média e Tecnológica. Parâmetros Curriculares Nacionais: Ensino Médio. Brasília: Ministério da Educação, 2001.

http://portal.mec.gov.br/seb/arquivos/pdf/blegais.pdf.

15 SANTOS, Wildson Luiz Pereira; PORTO, Paulo Alves. A pesquisa em ensino de química como área estratégica para o desenvolvimento da química. Quim. Nova, Vol. 36, No. 10, 1570-1576, 2013.

16 ALVIM; ZONATELLO, 2014 Op. Cit.

17 FERNÁNDEZ, Luigi Cuellar; GATICA, Mario Quintanilla; BLANCAFORT, Ainoa Marzàbal. La importancia de la Historia de la Química en la enseñanza escolar: análisis del pensamiento y elaboración 
Essa ideia de formação e ensino das ciências naturais a partir de uma orientação de cidadania e valores, pode permanentemente reler e compreender vários quadros teóricos para interpretar fenômenos científicos que hoje entendemos bem e é explicado por teorias atuais, que continuam a evoluir rapidamente. Esta perspectiva também nos permite compreender a relação entre a ciência e a cultura de um tempo específico, analisando assim a sua influência sobre o desenvolvimento e a consolidação de uma sociedade que compartilha valores se ressignificam sistematicamente. ${ }^{18}$

Deste modo, Díaz destaca que o enfoque CTS no ensino de ciências pretende tornar explícitas as relações entre ciência, tecnologia e sociedade à luz da $\mathrm{HC}^{19}$. Assim, discutir estas relações de forma contextualizada, “[...] concebendo a ciência como fruto da criação humana e suscetível às intempéries, desenvolvendo-se permeada pela ação reflexiva de quem sofre/age as diversas crises inerentes a esse processo de desenvolvimento" ${ }^{20}$, é fundamental para promovermos uma educação científica emancipadora.

Para dar uma resposta racional, razoável e coerente a este respeito, a hipótese que temos, é que a origem histórica surge das controversas e polêmicas das principais teorias da química, o processo de criação e desenvolvimento dos principais conceitos e metodologias científicas como resultado de um trabalho coletivo e uma construção humana, em que há intrigas, pressões e tensões, e, assim, analisar a complexidade da relação entre ciência - tecnologia - sociedade - comunicação (CTSC) ao longo da história, com as implicações da mudança dos processos sociais e convivência que ele tem gerado para a comunidade científica e a comunidade dos químicos, em especial. ${ }^{21}$

A HC e a educação CTS fornecem importantes subsídios para a compreensão da natureza da ciência, desmistificando a ciência de grandes gênios, imunes às atividades humanas, sociais e

de material didáctico de profesores en formación. Ciênc. Educ. (Bauru), [s.l.], v. 16, n. 2, p.277-291, 2010. FapUNIFESP (SciELO). http://dx.doi.org/10.1590/s1516-73132010000200001. p. 228.

${ }^{18}$ Esta idea de formación y enseñanza de las ciencias naturales desde una orientación de ciudadanía y valores permite releer y comprender permanentemente marcos teóricos diversos para interpretar fenómenos científicos que hoy comprendemos bien y que se explican mediante teorías vigentes, las cuales continúan evolucionando vertiginosamente. Esta perspectiva nos permite además conocer la relación entre la ciencia y la cultura de una época específica, analizando de esta forma la influencia de éstas en el desarrollo y consolidación de una sociedad determinada que comparte unos valores que se resignifican sistematicamente. p. (281).

${ }^{19}$ DiÁZ, J. A. A.; AlOnSO, A. V.; MAS, M. A. M.; ROMERO, P. A. Persistencia de las actitudes y creencias CTS en la profesión docente Revista Electrónica de Enseñanza de las Ciencias, Vol. 1, No 1, 1-27. 2002.

20 PINHEIRO, Nilcéia Aparecida Maciel; SILVEIRA, Rosemari Monteiro Castilho Foggiatt; BAZZO, Walter Antonio. Ciência, Tecnologia e Sociedade: a relevância do enfoque CTS para o contexto do Ensino Médio. Ciênc. Educ. (Bauru), [s.l.], v. 13, n. 1, p.71-84, abr. 2007, FapUNIFESP (SciELO), p. 19, http://dx.doi.org/10.1590/s1516-73132007000100005.

${ }^{21}$ FERNÁNDEZ, 2010. Op. Cit., p. 281: "Para dar una respuesta racional, razonable y coherente en este sentido, la hipótesis que sustentamos, es que se plantee el origen histórico, controversial y polémico de las principales teorías de la química, se muestre el proceso de creación y desarrollo de los principales conceptos y metodologías científicas como fruto de un trabajo colectivo y de una construcción humana, en la que hay intrigas, tensiones y distensiones, y se analice así la complejidad de las relaciones ciencia tecnología - sociedad - comunicación (CTSC) a lo largo de la Historia, con las implicaciones de transformación de los procesos sociales y de convivencia que ello ha generado para la comunidad científica en general y para la comunidad de los químicos en particular". 
ambientais e permite o desenvolvimento do senso crítico, traz a luz às influências políticas e culturais, que permearam e ainda permeiam o trabalho científico, apresentando indivíduos sujeitos à inquietações, possibilitando ao professor e ao estudante uma certa identificação e aproximação, que os permite refletir e se tornar parte, criando um ambiente propício para a reflexão-ação.

\title{
V. Elos possíveis
}

\author{
[...] é preciso que a educação esteja - em seu conteúdo, em seus \\ programas e em seus métodos - adaptada ao fim que se persegue: permitir ao \\ homem chegar a ser sujeito, construir-se como pessoa, transformar o mundo, \\ estabelecer com os outros homens relacooes de reciprocidade, fazer a cultura e a \\ bistória. $^{22}$
}

O conhecimento histórico busca compreender os processos humanos e suas relações com diferentes espaços e tempos, bem como, analisar as diferentes influências sociais, políticas, culturais e ambientais que culminaram na construção das sociedades. Deste modo, segundo Neves $^{23}$ ensinar química envolve fazer o aluno compreender uma atividade humana, que transforma o meio, seja natural ou artificial, portanto, ensinar química fora de seu contexto histórico e social é ignorar seu passado.

Compreender os interesses políticos e sociais envolvidos no desenvolvimento das ciências é despertar não somente o entendimento do conteúdo, mas ainda o senso crítico, necessários para aprendizagens da química e de sua relação com a prática da cidadania. Uma educação transformadora e contextualizada não pode mais se dar, exclusivamente, através de conteúdos oriundos de Leis imutáveis, de uma ciência infalível, construídos por grandes gênios - faz-se necessária à inserção dos aspectos humanos envolvidos no desenvolvimento desta ciência.

Santos considera que a HC em uma perspectiva CTS tem um papel muito importante, que é o de proporcionar um número variado de situações que podem mostrar de maneira ilustrativa as relações entre ciência-tecnologia-sociedade, permitindo, então, incursões interessantes dentro do modelo CTS, que não abordarão somente a aprendizagem de conteúdos científicos relevantes, mas também os aspectos tecnológicos e sociais neles envolvidos.

Com esta discussão, não só se conseguirá facilitar aos alunos a compreensão dos conteúdos científicos como também considerar-se-á outros efeitos extremamente valiosos: a percepção de uma ciência não separada em compartimentos estanques, mas sim uma "ciência" unitária, um todo global que, além disso, estaria em contínua evolução, interagindo de forma multidirecional com outros muitos fatores e saberes. Isto é, a imagem de uma ciência não dogmática, cujo caráter interdisciplinar seria

22 FREIRE, Paulo. Ação cultural para a liberdade e outros escritos. Rio de Janeiro: Paz e Terra, 1981., p. 21.

${ }^{23}$ NEVES, L. S; FARIAS, R. F. História da Química: um livro-texto para graduação. São Paulo: Átomo, 2008. 
destaque. E assim mesmo, se promoveria a reflexão para os problemas sociais. ${ }^{24}$

Para que isto aconteça é necessário que a educação escolar dê condições para que o aluno compreenda a natureza do contexto científico-tecnológico e seu papel na sociedade, esta compreensão virá, tão logo for adquirido conhecimentos básicos de HC, para compreender as limitações e potencialidades da ciência de forma a possibilitar ao cidadão conhecimento e fundamento que lhe permitam a tomada de decisões.

[...] os problemas mais graves que devem ser revistos no ensino são: a compartimentalização dos saberes e a incapacidade de articulá-los uns aos outros, uma vez que a aptidão para contextualizar e integrar é qualidade fundamental da mente humana e precisa ser desenvolvida e não atrofiada. ${ }^{25}$

A HC pode ser aplicada em diversos contextos, desde a aprendizagem da própria HC até o ensino CTS, onde utilizar exemplos, fatos e narrativas podem contribuir com o desenvolvimento do pensamento crítico.

Com essa linha de contribuições e interfaces entende-se, no mínimo, que a própria HCT é uma ferramenta relevante para o aprendizado científico e inovação tecnológica, ao invés de ser pura erudição, ilustração, reprodução ou modificação da "Cultura" de C\&T. Ela pode sim auxiliar, junto com outras áreas e atuações, a promover a cidadania em geral. [...] Existe um campo de CTS que aglutina aqueles que pensam sobre a política, sobre a inovação, sobre os mercados, sobre a educação e sobre o conhecimento público da C\&T e aí reside a HCT. ${ }^{26}$

Ainda, segundo Oliver é nesta perspectiva que as ciências e a tecnologia "[...] deixam de ser algo incompreensível e desconexo da sociedade e se mostram atreladas por seus imaginários e contextos específicos em que são apropriadas/criadas”. O significado da educação, tomado em um sentido sociológico, expressa-se como um enriquecimento da inteligência humana, com a qual é possível superar os desafios do meio em que se vive, que por ser dinâmico e mutável, exige dos indivíduos uma visão interdisciplinar e reflexiva.

${ }^{24}$ SANTOS, Soledad Esteban. La perspectiva histórica de las relaciones CienciaTecnología-Sociedad y su papel en la enseñanza de las ciencias. Revista Electrónica de Enseñanza de las Ciencias, Vol. 2, No3, 399-415 (2003) p. 404, “Trabajando con esas situaciones se atenderá no sólo al aprendizaje de los contenidos científicos correspondientes, sino al de los aspectos tecnológicos y sociales implicados en ellos. Con su discusión se conseguirá facilitar a los alumnos la comprensión de los contenidos científicos. Pero, además, hay que considerar otros efectos sumamente valiosos: se propiciaría la percepción de una ciencia no separada en compartimentos estancos, sino de una "ciencia" unitaria, un todo global que, además, estaría en continua evolución, interaccionando de forma multidireccional con otros muchos factores y saberes. Es decir, se propiciaría la imagen de una ciencia no dogmática, cuyo carácter interdisciplinar quedaría resaltado. Y asimismo, se promovería la reflexión hacia los problemas sociales".

25 PINHEIRO, 2007. Op. Cit., p. 79.

26 OLIVER, Graciela de Souza. História das ciências e das tecnologias e o campo de Ciência, Tecnologia e Sociedade (CTS). Revista Contemporaneos, Santo André, v. 10, p.1-24, maio 2010. p. 12 http://www.revistacontemporaneos.com.br/n10/artigos/historia-ciencias.pdf. 
Acreditamos que esta visão pode ser facilitada por meio de uma abordagem que associe os conhecimentos históricos e a dimensão CTS, possibilitando o desenvolvimento de um sentido crítico.

Então, entre os objetivos da educação encontra-se a formação de bons cidadãos, conscientes de sua responsabilidade de contribuir para o bem-estar e desenvolvimento social. E isto seria um objetivo particular da educação em ciências, mas que tem um caráter comum a toda educação, uma vez que contempla o indivíduo como um ser social que está vivendo com outros indivíduos. ${ }^{27}$

A HC em uma perspectiva CTS apresenta-nos a possibilidade de compreender a ciência como parte de uma teia de conhecimentos intrínsecos, que está relacionada com o mundo de forma dinâmica e não de forma estática, que está em permanente processo de construção e, assim, cada indivíduo influencia e é influenciado por ela. Da mesma forma, os avanços tecnológicos, as intempéries sociais e políticas e as interferências ambientais são frutos desta história socialmente construída.

A fecundidade da reflexão histórica sobre o conhecimento reside menos na apresentação do "sucesso" das teorias e personalidades, e mais na potencialidade que a História das Ciências possui em analisar a produção de um dado conhecimento, a partir de sua relação com o contexto social, cultural, intelectual, religioso e político-econômico no qual este conhecimento foi engendrado e desenvolvido. E esta análise contribui decisivamente para uma reflexão mais crítica sobre o "fazer" científico e sobre sua condição de objeto sociocultural de uma determinada sociedade, permitindo uma educação científica mais crítica e cidadã.

Neste sentido, a história como cultura tem um papel muito importante, compreender a interligação destes diversos fatores que influenciaram e influenciam o desenvolvimento da ciência e da tecnologia, é compreender a ciência como fruto da construção humana, dada a uma determinada época, segundo uma determinada demanda e de uma sociedade específica, que a caracteriza como uma atividade não neutra, tampouco ahistórica.

A ciência, enquanto discurso humano sobre a natureza, reflete a construção e organização dos conhecimentos sobre o mundo natural em determinado período. A organização destes conhecimentos em torno a uma lógica própria consiste na produção do conteúdo que esta área do conhecimento/ciência irá se deter. Deste modo, o conteúdo científico é selecionado, organizado e construído pelo homem, atendendo aos anseios, as necessidades e as experiências culturais do seu tempo histórico. $\mathrm{O}$ conhecimento científico não é autônomo em relação ao homem, como os positivistas entendiam a ciência, mas possuí uma natureza histórica. ${ }^{28}$

\footnotetext{
27 SANTOS, 2003. Op. Cit., p. 404. "Entonces, entre los objetivos prioritarios de la educación se encontraría la formación de buenos ciudadanos, conscientes de su responsabilidad para contribuir al bienestar y desarrollo social. Y éste sería un objetivo no particular de la educación en ciencias, sino que tiene un carácter común a toda la educación puesto que contempla al individuo como ser social que es, conviviendo con otros individuos."

28 ALVIM, Márcia Helena. História das Ciências e Ensino de Ciências: potencialidades para uma educação cidadã. In: VII SEMINARIO IBÉRICO/III SEMINARIO IBEROAMERICANO CTS EN LA ENSEÑANZA DE LAS CIENCIAS "CIENCIA, TECNOLOGÍA Y SOCIEDAD EN EL FUTURO DE LA ENSEÑANZA DE LAS CIENCIAS”, 6., 2012, Madrid, España. Anais... Madrid, España: Associação Ibero-americana CTS, 2012. p. 1 - 8., p. 03.
} 
Podemos inferir que um dos elos possíveis entre a HC e a educação CTS está contido na história cultural das ciências, pois esta compreende a ciência como um conjunto amplo de fatores que interligados possibilitaram sua construção, através do diálogo com a sociedade na qual é produzida.

A História Cultural das Ciências apresenta variadas possibilidades de ação e reflexão para o ensino de ciências, especialmente através de sua análise acerca da prática científica e da natureza da ciência enquanto objeto sociocultural. Neste sentido, acreditamos que a História Cultural das Ciências, além de ferramenta didática aos conteúdos científicos, apresentase como veículo reflexivo para os jovens que vivem uma contemporaneidade marcada decisivamente pela tecnociência e por seus impactos sócio-econômico-ambientais através de uma educação científica que valorize uma formação cidadã. ${ }^{29}$

Deste modo, é necessário buscar novas abordagens de ensino de ciências que contemplem o viés histórico, inserindo as conexões sociais, políticas, tecnológicas e socioculturais que contribuíram para a construção das ciências. Estas novas abordagens devem preconizar uma educação científica reflexiva e cidadã. ${ }^{30}$

Construir ambientes educativos que sejam eles próprios ambientes de cidadania, e permear o ensino substantivo da disciplina de princípios e valores que penetrem em questões relacionadas com alguns conteúdos da ciência, com a sua natureza e estatuto e com o lugar da história da ciência no ensino da ciência, não é subestimar a dimensão conceptual da disciplina, mas complementa-la com a dimensão formativa. ${ }^{31}$

Acreditamos que uma abordagem histórica, dentro da perspectiva de educação CTS, pode contribuir para a construção destes ambientes educativos promotores de reflexão. Esta proposta está sintetizada no quadro 1 que apresenta uma comparação entre quatro diferentes abordagens de ensino.

Tabela 1 - Abordagens no Ensino de Ciências - do Ensino de ciências tradicional ao Ensino de Ciências na abordagem da HC com foco CTS.

\begin{tabular}{|c|c|c|c|}
\hline $\begin{array}{l}\text { Ensino } \\
\text { Tradicional de } \\
\text { ciências }\end{array}$ & $\begin{array}{l}\text { Ensino na } \\
\text { abordagem CTS }\end{array}$ & $\begin{array}{c}\text { Ensino } \\
\text { abordagem da HC }\end{array}$ & \begin{tabular}{l}
\multicolumn{2}{c}{ Ensino na } \\
abordagem da $\mathrm{HC}$ \\
com foco CTS
\end{tabular} \\
\hline 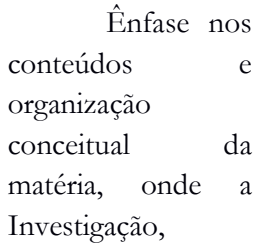 & $\begin{array}{l}\text { Matéria } \\
\text { organizada em temas } \\
\text { tecnológicos } \\
\text { sociais, enfatizando } \\
\text { as limitações e }\end{array}$ & $\begin{array}{l}\text { Compreensão da } \\
\text { construção da ciência como } \\
\text { atividade humana. }\end{array}$ & $\begin{array}{l}\text { Ensino } \\
\text { organizado em temas } \\
\text { CTS atrelado a } \\
\text { compreensão }\end{array}$ \\
\hline
\end{tabular}

${ }^{29}$ ALVIM, ZANOTELLO, 2014. Op. Cit., p. 353.

30 SANTOS, Maria Eduarda Vaz Moniz dos. Ciência como cultura: paradigmas e implicações epistemológicas na educação científica escolar. Química Nova, [s.1.], v. 32, n. 2, p.530-537, 2009. FapUNIFESP (SciELO). p. 534.

31 SANTOS, 2009. Op. Cit., p. 534 


\begin{tabular}{|c|c|c|c|}
\hline $\begin{array}{l}\text { observação, } \\
\text { experimentação } \\
\text { partem da teoria. }\end{array}$ & $\begin{array}{l}\text { potencialidades dos } \\
\text { mesmos. }\end{array}$ & & $\begin{array}{l}\text { construção da ciência } \\
\text { como atividade humana. }\end{array}$ \\
\hline $\begin{array}{l}\text { Ênfase no } \\
\text { método científico. }\end{array}$ & $\begin{array}{l}\text { Ênfase no } \\
\text { método científico. }\end{array}$ & $\begin{array}{l}\text { Questiona } \\
\text { método científico. }\end{array}$ & $\begin{array}{l}\text { Questiona "o" } \\
\text { método científico e } \\
\text { apresenta diferentes } \\
\text { pontos de vista. }\end{array}$ \\
\hline $\begin{array}{l}\text { A ciência é } \\
\text { apresentada como } \\
\text { um conjunto de Leis } \\
\text { e princípios para } \\
\text { explicar o universo } \\
\text { de modo infalível. }\end{array}$ & $\begin{array}{l}\text { A ciência é } \\
\text { apresentada como } \\
\text { área a ser explorada, } \\
\text { utilizando-a para } \\
\text { tomada de decisões e } \\
\text { julgamento de valor. }\end{array}$ & $\begin{array}{l}\text { A ciência é } \\
\text { apresentada como atividade } \\
\text { em construção, passível de } \\
\text { erros e sujeita às } \\
\text { intempéries } \\
\text { políticas, etc. }\end{array}$ & $\begin{array}{lr}\text { A ciência é } \\
\text { apresentada } & \text { como } \\
\text { atividade } & \text { em } \\
\text { construção, passível de } \\
\text { erros e sujeita às } \\
\text { intempéries sociais, } \\
\text { políticas, etc. Promove o } \\
\text { questionamento de } \\
\text { como estas influências } \\
\text { afetam (e afetaram) a } \\
\text { sociedade. }\end{array}$ \\
\hline $\begin{array}{l}\text { Apresenta } \\
\text { "uma" verdade } \\
\text { científica e mostra } \\
\text { sua aplicabilidade } \\
\text { como algo } \\
\text { inquestionável. }\end{array}$ & $\begin{array}{l}\text { Utiliza “as" } \\
\text { verdades científicas } \\
\text { para prever } \\
\text { consequências das } \\
\text { diferentes } \\
\text { tecnologias inseridas } \\
\text { na sociedade em } \\
\text { relação às questões } \\
\text { sociais, ambientais, } \\
\text { éticas, etc. }\end{array}$ & 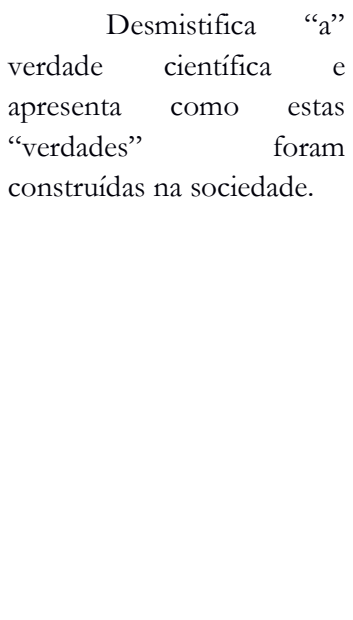 & $\begin{array}{l}\text { Através dos } \\
\text { conteúdos e produções } \\
\text { científicas discute as } \\
\text { consequências das } \\
\text { diferentes tecnologias } \\
\text { inseridas na sociedade } \\
\text { em relação às questões } \\
\text { sociais, ambientais, } \\
\text { éticas, etc., porém } \\
\text { tomando consciência de } \\
\text { que as Leis } \\
\text { "vencedoras" foram e } \\
\text { ainda são questionadas e } \\
\text { passíveis } \\
\text { modificação. }\end{array}$ \\
\hline $\begin{array}{l}\text { Apresenta a } \\
\text { construção do } \\
\text { conhecimento } \\
\text { científico como um } \\
\text { uma atividade } \\
\text { universal. }\end{array}$ & $\begin{array}{l}\text { Apresenta o } \\
\text { desenvolvimento } \\
\text { tecnológico atrelado } \\
\text { à ciência e } \\
\text { dependente das } \\
\text { decisões humanas e } \\
\text { interesses sócio- } \\
\text { políticos-ambientais. }\end{array}$ & $\begin{array}{lr} & \text { Apresenta } \\
\text { construção } & \text { do } \\
\text { conhecimento } & \text { científico e } \\
\text { tecnológico } & \text { como } \\
\text { construção } & \text { humana } \\
\text { suscetível às interferências e } \\
\text { demandas sociais, políticas, } \\
\text { econômicas, ambientais, } \\
\text { etc. da época. }\end{array}$ & $\begin{array}{l}\text { Apresenta a } \\
\text { construção do } \\
\text { conhecimento científico } \\
\text { e tecnológico como } \\
\text { construção humana } \\
\text { suscetível às } \\
\text { interferências } \\
\text { demandas sociais, } \\
\text { políticas, econômicas, } \\
\text { ambientais, etc. da } \\
\text { época. }\end{array}$ \\
\hline
\end{tabular}


Khronos, Revista de História da Ciência

ISSN 2447-2158 - no 4, agosto 2017

\begin{tabular}{|c|c|c|c|}
\hline \begin{tabular}{l}
\multicolumn{3}{c}{ Apresenta } \\
fenômenos \\
isolados, divididos \\
em disciplinas \\
específicas r sem \\
diálogo com as \\
demais áreas de \\
conhecimento.
\end{tabular} & \begin{tabular}{l}
\multicolumn{3}{c}{ Apresenta } \\
os fenômenos a \\
partir de um \\
contexto \\
interdisciplinar.
\end{tabular} & $\begin{array}{l}\text { Apresenta os } \\
\text { fenômenos a partir de um } \\
\text { contexto interdisciplinar. }\end{array}$ & $\begin{array}{l}\text { Apresenta os } \\
\text { fenômenos a partir de } \\
\text { um contexto } \\
\text { interdisciplinar. }\end{array}$ \\
\hline $\begin{array}{l}\text { A análise } \\
\text { dos fatos, quase } \\
\text { sempre, é exata e } \\
\text { imparcial. }\end{array}$ & 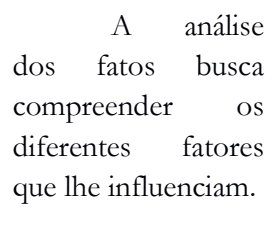 & $\begin{array}{l}\text { A análise dos fatos } \\
\text { é realizada à luz da } \\
\text { historiografia. }\end{array}$ & $\begin{array}{l}\text { A análise dos } \\
\text { fatos é realizada à luz da } \\
\text { historiografia, buscando } \\
\text { compreender os } \\
\text { diferentes fatores que } \\
\text { lhe influenciam. }\end{array}$ \\
\hline $\begin{array}{l}\text { Objetiva } \\
\text { compreender o } \\
\text { mundo natural, } \\
\text { apesar de apresentá- } \\
\text { lo de forma } \\
\text { fragmentada. }\end{array}$ & \begin{tabular}{l}
\multicolumn{2}{c}{ Objetiva } \\
principalmente \\
compreender as \\
implicações sociais, \\
ambientais, etc. dos \\
problemas ligados às \\
ciências e a \\
tecnologia.
\end{tabular} & $\begin{array}{l}\text { Objetiva fornecer } \\
\text { subsídios para a } \\
\text { compreensão da natureza } \\
\text { da ciência, permitindo o } \\
\text { desenvolvimento do senso } \\
\text { crítico destacando suas } \\
\text { influências políticas e } \\
\text { culturais, apresentando } \\
\text { indivíduos sujeitos a estas } \\
\text { inquietações, possibilitando } \\
\text { uma certa identificação e } \\
\text { aproximação, que permite } \\
\text { refletir e se tornar parte, } \\
\text { criando um ambiente } \\
\text { propício para a reflexão- } \\
\text { ação. }\end{array}$ & $\begin{array}{l}\text { Objetiva } \\
\text { fornecer subsídios para } \\
\text { compreensão da } \\
\text { natureza da ciência, } \\
\text { permitindo r o } \\
\text { desenvolvimento do } \\
\text { senso crítico destacando } \\
\text { suas influências políticas } \\
\text { e culturais, } \\
\text { apresentando indivíduos } \\
\text { sujeitos a estas } \\
\text { inquietações, } \\
\text { possibilitando uma certa } \\
\text { identificação } \\
\text { aproximação, } \\
\text { permite refletir e se } \\
\text { tornar parte, criando um } \\
\text { ambiente propício para } \\
\text { a reflexão-ação. }\end{array}$ \\
\hline
\end{tabular}

Fonte: Adaptado de OLIVEIRA; OLIVEIRA, 2016²

A tabela 1 nos mostra as diferenças entre as diversas abordagens no ensino de ciências, não se configurando como uma análise final, mas buscando destacar as potencialidades de uma abordagem que articule a HC e a educação CTS. Através destas reflexões, podemos constatar que a preocupação tanto da educação CTS quanto da HC, relaciona-se à construção de uma postura mais crítica em relação à ciência, ao mundo e à sociedade, postura esta que necessita ser desenvolvida em etapas, com atenção contínua e permeada por diferentes ações. Desta forma,

32 OLIVEIRA; OLIVEIRA, 2016. Op. Cit. 
este estudo aponta para uma proposta pedagógica que relacione a educação CTS com a HC, podendo esta ser percebida através de três aspectos, apresentados abaixo:

I - Percepção: Olhar o mundo de forma diferente, através de uma educação científica que seja capaz de contribuir para um conhecimento significativo, com ênfase nas questões científicas, tecnológicas e sociais de interesse dos alunos, apresentando o conteúdo científico a partir de sua historicidade;

II - Questionamento: Promover uma educação científica questionadora e não dogmática, que possa contribuir na busca de respostas às questões que envolvem aspectos científicos e tecnológicos e suas implicações sociais, políticas e ambientais ao longo da história e nos dias atuais e futuros;

III - Ação: Desenvolvido os dois primeiros aspectos, percepção e questionamento, podemos seguir para uma educação ativa, onde o professor seja capaz de estimular e desenvolver competências essenciais para que os indivíduos sejam capazes de lidar com problemas reais de diferentes naturezas, tendo condições de realizarem uma leitura crítica da realidade e atuarem conscientemente na mesma.

Neste cenário, Solbes destaca as competências essenciais de uma educação científica que valorize as discussões da HC com enfoque CTS:

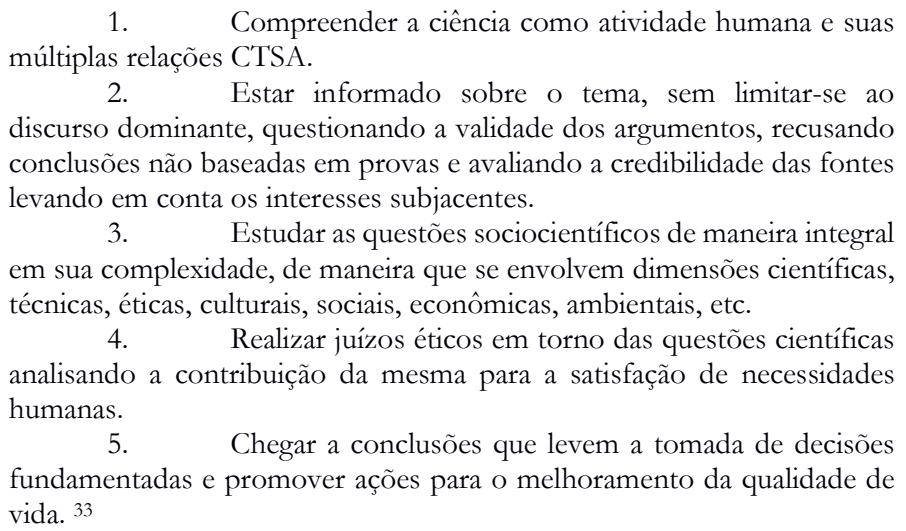

1. Compreender a ciência como atividade humana e suas múltiplas relações CTSA.

2. Estar informado sobre o tema, sem limitar-se ao discurso dominante, questionando a validade dos argumentos, recusando conclusões não baseadas em provas e avaliando a credibilidade das fontes levando em conta os interesses subjacentes.

3. Estudar as questões sociocientíficos de maneira integral em sua complexidade, de maneira que se envolvem dimensões científicas, técnicas, éticas, culturais, sociais, econômicas, ambientais, etc.

4. Realizar juízos éticos em torno das questões científicas analisando a contribuição da mesma para a satisfação de necessidades humanas.

5. Chegar a conclusões que levem a tomada de decisões fundamentadas e promover ações para o melhoramento da qualidade de vida. 33

Assim, o processo de reconstrução do ensino de química, através da HC e educação CTS, mostra-se como uma alternativa interessante para esta finalidade, porém deve-se levar em conta o necessário empenho no aprofundamento sobre a historiografia da HC, com a finalidade de superar antigas concepções sobre as ciências, que levaria a uma educação CTS acrítica.

A análise dos referenciais teóricos vistos até aqui apresenta-nos um panorama bastante positivo para adotarmos uma abordagem do ensino de ciências que dialogue a HC e a educação CTS. Esta relação promove a ruptura das fronteiras entre os saberes e nos direciona em busca de um ensino problematizador, humano e reflexivo, atingindo nosso objetivo na formação de cidadãos mais críticos e, quiçá, capazes de transformar a sociedade. Sem dúvida, este é um trabalho árduo, que requer um esforço centrado na reflexão/ação, articulado a uma rede de

33 SOLBES, J. Contribución de las cuestiones sociocientificas al desarrollo del pensamiento crítico (II): Ejemplos. Revista Eureka sobre Enseñanza y Divulgación de las Ciencias 10(2), 171-181, 2013, p. 180. 
saberes que possam relacionar os conhecimentos científicos e tecnológicos aos seus contextos culturais, sociais, ambientais e políticos.

\section{Considerações finais}

Reconhecendo que a HC e a educação CTS devem modificar o processo de ensinoaprendizagem em ciências, sendo capazes de desenvolver uma educação mais crítica, investigativa, reflexiva e inovadora, que possibilite a construção de novas formas de ensinar e aprender, observamos um universo de possibilidades que podem substituir um ensino tradicional, por um ensino de ciências plural que leve em conta aspectos culturais, sociais e ambientais.

Deste modo, discordamos da proposta de HC como um instrumento pedagógico ou, ainda, de uma educação CTS como, apenas, a realização de contextualização de conteúdos químicos. A inserção da HC numa perspectiva CTS está muito além disto, ela perpassa a consolidação de conteúdos e remete à reflexão dos significados sobre a ciência para as sociedades desta ou de outra temporalidade. A HC numa perspectiva CTS nos apresenta como os aspectos sociais e culturais são intrínsecos à prática científica, e, portanto, a compreensão do conhecimento como expressão humana no entendimento da realidade natural que o envolve é fundamental para a compreensão do fazer científico.

O processo de reconstrução do ensino de química, através da HC e da educação CTS, mostra-se como uma alternativa interessante para esta finalidade, porém deve-se superar antigas concepções de HC, associadas a uma educação CTS superficial. Apesar de vários estudos apontarem para as vantagens da utilização de HC e educação CTS, é de se observar que muitos destes trabalhos ainda abordam a $\mathrm{HC}$ apenas como complementos da aprendizagem, ou como ferramentas para explicar certos conteúdos da Química, diferindo radicalmente de nossa proposta, ou seja, da compreensão da construção do conhecimento científico e tecnológico através de sua historicidade.

A análise dos referenciais teóricos vistos até aqui apresenta-nos um panorama bastante positivo para adotarmos uma abordagem de ensino de ciências que dialogue a HC e a educação CTS. Esta relação promove a ruptura entre as fronteiras dos saberes e nos direciona na busca de um ensino mais problematizador, humano e reflexivo com os objetivos de formar cidadãos mais críticos e, quiçá, capazes de transformar a sociedade. Sem dúvida, este é um trabalho árduo, que requer um esforço centrado na reflexão/ação, articulado a uma rede de saberes que possa relacionar os conhecimentos científicos e tecnológicos aos seus contextos culturais, sociais, ambientais e políticos.

Tão logo esta reflexão seja feita, poderemos caminhar em direção a uma educação científica reflexiva que entenda a química como um elemento sociocultural, fruto de todas estas interações e promova uma educação que prepare nossos alunos para cidadania emancipadora. 